\title{
Geografías de un territorio de frontera: La Chimba, Santiago de Chile. Siglo XVII - XXI ${ }^{1}$
}

\author{
Francisca Márquez ${ }^{2}$ y Ricardo Truffello ${ }^{3}$
}

\begin{abstract}
RESUMEN
Se indaga en las representaciones que subyacen en las cartografías y representaciones de un territorio de frontera como es La Chimba de Santiago, entre los siglos XVII y XXI. Estas representaciones se abordan a través de: a) cartografía georreferenciada contemporánea; b) cartografía histórica; c) y los mapas cognitivos de los habitantes. En un ejercicio de lectura e interpretación de las representaciones de científicos y de nativos de La Chimba, el estudio asume desafíos epistemológicos en torno a la "naturaleza de la cartografía" e incursiona en la geografía de las representaciones. Esta investigación se pregunta por la construcción social y subjetiva de la geografía representada por estudiosos y habitantes de La Chimba. La investigación permite concluir que La Chimba se ha construido histórica y socialmente como territorio de frontera. Desde la mirada de la cartografía histórica, La Chimba fue representada siempre como territorio indomable, difícil de ordenar y representar. Desde la mirada de los mapas cognitivos de sus habitantes, La Chimba es un territorio de diversidad multicultural y del habitar subalterno. La georreferenciación contemporánea a su vez, contextualiza el análisis, y contribuye a confirmar la tesis de La Chimba como un territorio de frontera al lado norte del río Mapocho.
\end{abstract}

Palabras clave: Geografía, georreferenciación, mapas cognitivos, territorio de frontera.

\begin{abstract}
This article investigates the representations that underlie cartography and representations of a frontier territory such as La Chimba, Santiago, between the 17 th and 21 th centuries. These representations are examined and analyzed by three means of applied cartography: a) historical maps of the city of Santiago; b) geo-referencing techniques provided by contemporary geographical mapping; and c) cognitive maps from the area's inhabitants -both immigrants and Chileanscreated to portray their own territory and habitat. By examining the portrayals as described in three voices, we are able to create a dialogue among three methodologies for spatial representation in order to adequately understand this frontier territory, while, at the same time, achieving comprehension of the genesis of an inhabited urban area, of its social hierarchies and processes of racial mixing.
\end{abstract}

Key words: Geography, geo-referencing, cognitive maps, frontier territory.

\footnotetext{
1 Este artículo presenta resultados del proyecto FONDECYT N 1095083. La Ciudad de los Otros. Inmigrantes en territorios de frontera: La Chimba en el siglo XX. Artículo recibido el 7 de marzo de 2012, aceptado el 7 de noviembre de 2012 y corregido el 17 de diciembre de 2012.
}

\footnotetext{
2 Departamento de Antropología, Universidad Alberto Hurtado (Chile).

Email: fmarquez@uahurtado.cl

3 Escuela de Diseño, Universidad Adolfo Ibáñez (Chile). E-mail: ricardo.truffello@uai.cl
} 
La investigación se pregunta por los distintos modos de representar a través del tiempo, La Chimba de Santiago, territorio emplazado al norte del río Mapocho. Dicha pregunta se aborda a partir de la cartografía histórica de quienes pensaron y soñaron la ciudad de Santiago durante los siglos XVII al XIX; y los mapas cognitivos de quienes hoy lo habitan en pleno siglo XXI. Para contextualizar e introducir al lector a la geografía de las representaciones pasadas y presentes, se describe a través de un análisis sociodemográfico territorializado, La Chimba del siglo XX según los censos de 1992 y 2002. A través de esta lectura, se advierte la vigencia que posee La Chimba como territorio de frontera, en términos de la consolidación de una población inmigrante y socioculturalmente diversa en su habitar. En términos conceptuales, esta segunda lectura, sigue los análisis clásicos de la escuela de "ecología urbana y demografía" de la Universidad de Chicago (Burgess, 1963).

En un doble ejercicio de lectura e interpretación de los mapas de científicos y de nativos de La Chimba, el estudio asume desafíos epistemológicos en torno a la "naturaleza de la cartografía" (Harley, 2005) e incursiona en la geografía de las representaciones. Sin embargo, más que abandonar radicalmente factores de causalidad y objetividad esta investigación avanza hacia preguntas que ponen el acento en la interpretación de la cartografía y aspectos que dicen relación con la construcción social y subjetiva de los fenómenos representados por los estudiosos y habitantes de La Chimba (Bailly, 1989). De esta forma la geografía de las representaciones permite articular conceptos como representaciones, imaginarios, ideología e identidad cultural en la búsqueda de la trama de significados que sustentan las sociedades y su relación con el espacio (Bustos, 2005). El artículo entra en este debate epistemológico a través de la hipótesis que los territorios de La Chimba siempre han sido concebidos y representados como el "otro lado" de la ciudad, como contracara de la ciudad oficial, ellos conforman desde siempre un "territorio de frontera".

\section{De la geografía de las representaciones}

Indagar en la geografía de las representaciones (históricas y actuales) es también avanzar hacia los procesos de construcción social del espacio, entendido como la manufactura cultural de la ciudad de Santiago (De Castro, 1997). En estos términos, la investigación se inscribe en una perspectiva constructivista de la geografía, en tanto no da por evidente la materialidad del espacio, sino que indaga en los procesos que la hicieron posible, así como las oportunidades que esa misma materialidad permite a la construcción de representaciones y prácticas sociales. Porque cada época, cada sociedad produce, a través de sus prácticas sociales cotidianas y su lenguaje, una estructura imaginaria, es que una geografía de las representaciones es también e inevitablemente, histórica. Asumir un enfoque constructivista de la geografía, supone entonces replantearse el concepto de espacio no solo como un espacio geométrico sino como un espacio vívido, como un lugar antropológico dotado de significado (Augé, 1992). Ahondar en el problema de las representaciones del espacio y el territorio (Bailly, 1989) es asumir que representar conlleva la imposibilidad de la reproducción mimética. Más bien, las representaciones, a nivel de la lógica cartográfica y positivista (Harley, 2005) no son fotografías, en ellas participan también intereses institucionales y subjetivos.

En esta investigación, la espacialidad es leída desde la materialidad y lo imaginario (Bailly, 1989); no hay espacio material que no sea cargado de significado, y difícilmente encontraremos un significado cuyo anclaje no sea espacial y temporal. El constructivismo territorial resulta justamente de la significación del espacio. El universo simbólico (ideologías territoriales, valores patrimoniales, memoria colectiva, sentimientos de identidad en particular) de las estructuras cognitivas del sujeto social encuentra un campo de referencias sólidas en las estructuras objetivas del espacio geográfico. Estas aportan, a cambio, argumentos de identidad, hitos que restablecen la memoria colectiva para las sociedades que los producen (Di Meo, 1999: 91). Es en estos espacios significados que las prácticas sociales deambulan, transitan y se alimentan dando forma y colorido al territorio. La interacción social y la percepción hacen entonces del espacio un lugar. De allí que un mismo fragmento de ciudad de territorio, puede ser construido y representado de diferentes formas según los puntos de vista 
(Bourdieu, 1993). Así como las acciones del sujeto habitante se configuran dentro de una lógica compartida, así también, esos lugares construidos modelan esas tramas de sentido y las acciones que en ellos se concretan (Lindón, 2007).

La relación entre realidad y representación cartográfica es siempre una construcción cultural e histórica. Los mapas poseen una retórica, un relato; ellos "son una forma de ver el mundo", y "al tiempo que el mapa nunca es la realidad, de cierta manera contribuye a crear una realidad diferente... Defino la cartografía como un organismo de conocimiento teórico y práctico que emplean los cartógrafos para construir mapas como un modo determinado de representación visual. Por supuesto que el asunto es históricamente específico: las reglas de la cartografía varían en las distintas sociedades" (Harley, 2005: 189)

En esta perspectiva nuestra investigación avanza hacia un análisis de la cartografía histórica para caracterizar los rasgos del territorio de La Chimba. El análisis se aproxima a la propuesta de Harley (2005) en el sentido de considerar mapas y planos como fuentes de conocimiento de la historia cultural y social. Así por tanto, esta investigación incluye los contextos sociales en la interpretación de los primeros mapas de La Chimba. Los mapas en tanto artefactos culturales, disciplinan, normalizan y estructuran la idea del mundo. Los mapas son en este sentido, imágenes con códigos históricamente específicos, hablan acerca de los mundos sociales. El mapa está dotado de historicidad: "Tanto a través de su contenido como de sus formas de representación, el trazado y el uso de los mapas han sido influidos por la ideología. No obstante, estos mecanismos solo pueden comprenderse en situaciones históricas específicas" (Harley, 2005: 108). La cartografía es un discurso político para la obtención y sostenimiento del poder; a través de su lenguaje visual resume y enmarca los derechos territoriales y los derechos de propiedad. La cartografía -nos recuerda Harley- ha sido así un arma intelectual del Estado moderno; del discurso científico y el político. En este sentido, más que ver en la cartografía una ciencia positiva, objetiva y exacta, la representación cartográfica res- ponde siempre a un tiempo y a una cultura que la construye.

Ciertamente, los contextos de producción -social, histórico, político y cultural-, pueden ser determinantes en las formas que adquiera una determinada cartografía. Antiguamente, en la parte inferior del plano de un edificio se situaba la fachada principal y la puerta de acceso y en el mapa de un territorio se leía, la parte baja, como el punto "desde" donde se viene o se está y la parte superior la dirección "hacia" donde se va. Es por ello que, en la cartografía histórica de Santiago, se puede observar que en esos planos va girando la posición que toman los puntos cardinales en relación con las coordenadas verticales y horizontales del espacio gráfico. Ello permite significar las circunstancias históricas en las cuales ellos fueron realizados. Las variaciones, como se verá, son clara expresión de decisiones estratégico militar, pero también de las utopías e idearios que subyacen bajo la forma de la ciudad en ese específico contexto histórico (Márquez, 2005). La cartografía histórica, en este sentido, contiene y expresa los idearios y narrativas dominantes de las utopías urbanas. A través del registro y significación de una forma arquitectónica, urbana o paisajística se instalan las ideas y utopías de la ciudad ideal. Preguntarse por los imaginarios tras la cartografía histórica exige preguntarse por las construcciones fundacionales que contribuyen o contribuyeron a hacer inteligible la experiencia de vida en ella. Los imaginarios en estos términos, nos hablan de cómo los que habitan, los que escriben y cartografían la ciudad, imaginan e inventan formas de vida urbana (Silva, 1996).

En este ejercicio de construcción cartográfica, no solo participan cartógrafos, geógrafos y científicos, también el "nativo" ha estado presente en la lectura y factura de estas cartografías. Harley nos propone por ejemplo, develar la paradoja de la participación de los indios en el cálculo y trazo de los mapas que luego se usaron para despojarlos de sus tierras en Inglaterra del siglo XVIII. Este ejercicio permite una reflexión del correlato cultural en torno a la elaboración de un mapa, los diferentes intereses e interpretaciones que se generan en torno a ellos y cómo los nativos significan y participan con sus propias representaciones del territorio. Ob- 
servar las representaciones de unos y otros, posibilita también dar cuenta de los silencios, los vacíos, las ausencias y los llenos de estas imágenes que hablan los territorios ordenados, domesticados y apropiados por los que transitan por él. En estos términos, la inclusión del "nativo" nos permite dejar de pensar el espacio simplemente como un recipiente. $\mathrm{Y}$ en cambio invita a pensar el espacio como una dimensión, que junto a otras, hace parte del complejo juego de interacciones que construyen sociedad. Así como el poder, bajo la forma de científicos y autoridades, participa en la construcción de la cartografía de su tiempo, igualmente las formas espaciales son representadas por los grupos que visibilizan otras maneras de ser, de relacionarse e interactuar con el entorno. No hay resistencia o poder que no comprometa nuevas formas de representarse el espacio. Así, el espacio no puede ser concebido sino como producción social, y en tanto tal, como resultado contingente de las interacciones sociales, dinámico y en constante proceso de transformación. El reto de las ciencias sociales es interpretar la configuración que muestran los diferentes tipos de espacialidades sociales o de relaciones espacio-temporales que dan cuenta de las geografías del poder que están en juego (García y Aramburo, 2009).

La propuesta de esta geografía humana y constructivista parece especialmente pertinente al estudio de espacios que por sus particulares características, son transversales y porosos a la diversidad social. Leer los lugares como intersección de múltiples geografías, es también abrirse a una mirada que rompe la concepción de las unidades socioespaciales como homogéneas y esenciales. Es la posibilidad cierta de observarlos como resultado de las interacciones y los condicionantes mutuos entre espacio y sociedad. El reconocimiento a las múltiples voces de un espacio, permiten pensar las dimensiones políticas e identitarias en su construcción, con todo lo que ellos poseen de conflictos, confrontaciones y creación. Así también, poner en diálogo a los distintos actores que participan en la configuración espacial, posibilita conciliar lo particular con lo estructural, e incorporar "los sentidos de lugar" mediante los cuales se configuran las subjetividades colectivas y las formas de apropiación simbólica del espacio, así como las condicionantes propias de su localización en una estructura de dominación mayor (García y Aramburo, 2009).

Avanzar hacia una cartografía social de las representaciones permite ciertamente un diálogo de saberes territoriales. Y sobre todo poner en diálogo representaciones y prácticas concretas de grupos sociales que la representación cartográfica de la autoridad pública y/o científica suele invisibilizar. En estos términos, sumar a la representación "oficial" y/o científica las percepciones y representaciones de los habitantes del territorio, es también legitimar este saber "nativo" y ampliar el conocimiento comprensivo sobre este espacio geográfico. Es asumir a unos y otros, especialistas y habitantes, como sujetos activos en producción, análisis e interpretación de los datos y representaciones de su territorio. Los grupos se apropian del espacio que habitan o controlan, también por medios afectivos y simbólicos, al semantizar los espacios y atribuirles, con sus prácticas y representaciones, sentidos de pertenencia e identidad.

En La Chimba, espacialidad porosa y de interacciones multicultural, se hace especialmente pertinente avanzar hacia una cartografía social de las representaciones. Apostada al norte del río Mapocho y al norte del casco histórico de la ciudad de Santiago, La Chimba es un territorio privilegiado para observar las relaciones entre la sociedad republicana blanca del lado sur del río, y las minorías étnicas de migrantes y trabajadores empobrecidos al lado norte. En estos términos, La Chimba y el río Mapocho conforman un territorio de frontera, entendido este como el lugar donde sociedades diversas construyen de manera activa los límites y diferencias en sus prácticas y representaciones. Un territorio de frontera es en estos términos una franja de disputa entre culturas y grupos sociales diversos, por el poder y el control de los modos de ocupación, uso y significación de dicho territorio. Dinámica de estructuración social distinta por cierto a la de las sociedades mayores, como es el casco de aquella que regula y mandata la ordenada cuadrícula del casco histórico de la ciudad de Santiago, al lado sur del río Mapocho. 


\section{Itinerario de una investigación}

Para responder a la pregunta central de esta investigación -que dice relación con las características representacionales del territorio de la Chimba a lo largo de la historia-, se optó por una investigación fundamentalmente cualitativa. Esta investigación transita entre la geografía y la antropología, y por ende se inicia con un ejercicio de observación y caracterización sociodemográfica del territorio de La Chimba contemporánea a través del análisis de información censal georreferencial ${ }^{4}$. El análisis demográfico a nivel de manzana, centrado principalmente en los inmigrantes y sus características sociodemográficas ${ }^{5}$, permitió contextualizar el análisis de las características representacionales de este territorio y avanzar en algunas evidencias empíricas que dan cuenta de sus particularidades -étnicas, territoriales y de conectividad- en relación al centro histórico y fundacional de la ciudad de Santiago. El análisis desde los indicadores que arroja el Censo de Poblaciones piensa el espacio como soporte de variables socioeconómicas -producto de la actividad económica, personas que se movilizan y factores demográficos y de bienestar-. En estos términos no dialoga con la propuesta de una geografía constructivista, pero otorga un contexto para la interpretación y lectura de las representaciones cartográficas históricas y los mapas cognitivos de los habitantes del lugar. Enfocar la diferenciación espacial al interior de un territorio de frontera como es La Chimba, desde la cuantificación y georreferenciación de determinadas variables, nos permite evidenciar tendencias en el espacio así como describir las formas espaciales sobre las cuales se des-

4 A nivel de manzana, esta información permite establecer patrones territoriales de forma detallada y concisa, independiente de los límites administrativos y políticos de la ciudad. Este análisis se realiza a través de series temporales basadas en informaciones de catastros totalizantes, tales como los censos de población. Ello permite inferir conclusiones consistentes con respecto a la realidad de un territorio y su entorno (Truffello, 2011).

5 Puntualmente se realizan interpolaciones de precios de suelo, las que son representadas en zonas homogéneas y analizadas en toda la dimensión de esta variable, entendiendo que los valores de suelo actúan como un factor de resumen de otros datos, tales como usos de suelo, flujos de personas y calidad de servicios disponibles (Núñez \& Shovelin, 2002). pliega el fenómeno estudiado. Permite a su vez, avanzar en la caracterización de algunos rasgos de "frontera" de este territorio de La Chimba, rasgos que luego serán interrogados a través de la interrelación de las representaciones. En estos términos, esta investigación instala la georreferenciación al servicio de la pregunta de investigación por la constitución y significación del espacio.

A partir de esta caracterización sociodemográfica, la investigación profundiza y se detiene en: a) las representaciones de La Chimba a partir de la cartografía de científicos entre el siglo XVII y XIX; b) y las representaciones de la Chimba a partir de los mapas cognitivos de actuales habitantes de La Chimba en el siglo XXI. El objetivo es hacer una lectura comprensiva del proceso de construcción y configuración de las representaciones sociales de este territorio. Interesan las representaciones desde "arriba", esto es, de viajeros y científicos vinculados y mandatados por gobernantes e institucionalidad pública (siglos XVII y XIX), y representaciones desde "abajo", esto es, de los habitantes del territorio en pleno siglo XXI.

En una primera instancia, nuestra investigación parte por describir y analizar algunos de los planos de archivos históricos de La Chimba, desde el siglo XVI al siglo XXI. Para ello, se revisan los planos históricos de la planta de la ciudad de Santiago, centrándose en aquellos en que aparece representada La Chimba y el río Mapocho como frontera en relación al centro de Santiago. El levantamiento de la información geográfica dialoga con los antecedentes sociohistóricos y los contextos en que se produjeron estos planos del antiguo barrio La Chimba.

Los planos y mapas históricos en tanto fuentes secundarias, son leídos y analizados no solo en su cualidad de soportes cartográficos y realistas de un territorio; sino también como imágenes construidas desde el imaginario y el contexto de quien lo mandata y produce. Tal como veremos, esta planimetría puede no solo explicar aspectos de geopolítica sino también enriquecer nuestros conocimientos sobre mentalidades, imaginarios y utopías de la época. Las referencias cartográficas sintetizan en este sentido, el imaginario geopolítico de su tiempo (Rojas Mix, 2006). 
Los mapas cognitivos de los habitantes de La Chimba en cambio, nos acercan a la cartografía simbólica (a diferencia de la cartografía física) -expresada en la construcción de croquis- da cuenta de límites metafóricos, imaginados, de hitos, de demarcaciones que indican y unen territorios a una memoria colectiva, a una manera de hacer las cosas que enlaza y da sentido (De Castro, 1997, 2005). En este sentido, mediante los croquis se representa la relación significante del sujeto a su espacio. La palabra, el relato de vida, constituye el soporte de esta cartografía simbólica. Para los mapas cognitivos, se entrevistó a 40 chilenos e inmigrantes residentes en La Chimba y se los invitó a dibujar libremente la ciudad de Santiago y el barrio de La Chimba.

Para los planos históricos así como para los mapas cognitivos, se analiza: a) La imagen urbana (Lynch, 1998), entendida como un conjunto de estructuras significativas ligadas a la orientación y al reconocimiento de la diversidad morfológica de la ciudad como conjunto y de La Chimba en específico. En especial se profundiza en el análisis de la representación del paisaje y el emplazamiento de la arquitectura. b) Los lugares significados a través de símbolos e indicaciones textuales -en especial para los planos históricos-; y las prácticas, trayectos cotidianos y marcas sobre el espacio que le permiten al habitante actual reconocerse e identificarse.

\section{Itinerario de La Chimba del siglo XVII al XXI}

Las tierras de La Chimba se sitúan -desde tiempos coloniales (siglos XVI-XVIII)- al norte de la ciudad de Santiago, entre las aguas del río Mapocho hasta el cerro Blanco, y entre el cerro San Cristóbal y el antiguo ramal del río La Cañadilla, de este a oeste. Esta ubicación, junto a la presencia inca en toda el área, confirieron a este territorio el nombre de Chimba, palabra de origen quechua que significa "de la otra orilla" o "de la otra banda del río" (Lavín, 1947: 64; Rosales 1948: 52). Con objeto de operacionalizar los límites del territorio de La Chimba, para efectos de ese estudio, y en estrecha correspondencia a los antecedentes de la historiografía, éste comprende todo el territorio al norte del río Mapocho de Santia- go. Siendo los límites, por el norte, el cerro Blanco; por el sur, avenida Santa María; por el oriente, el cerro San Cristóbal y por el poniente, Vivaceta.

Desde sus inicios el territorio de La Chimba tomó la forma de arrabal o "trastienda" de la ciudad fundacional. Territorio de los extramuros, se caracterizó por su importante presencia indígenas, muchos de ellos artesanos y desarraigados de las encomiendas ${ }^{6}$. "A esta masa imponderable e incontrolable, que se desprendía continuamente de las encomiendas, se fueron agregando otros grupos de negros horros, mestizos de color, mestizos criollos y aun españoles. Se agruparon en las ciudades principales formando barrios populares, La Ollería y La Chimba en Santiago" (Mellafe, 1959: 120). Una de las primeras reconfiguraciones poblacionales que experimentan las tierras de La Chimba después de fundada la ciudad, se genera por la relocalización de grupos de población mitmakuna (en su mayoría diaguitas incas) que ocupaban las tierras ubicadas a los pies del cerro Huelén (Álvarez, 2011). Más tarde se sumaron a La Chimba, grupos de población errante, producto de la exclusión de la encomienda en los sistemas de trabajo de la época. De acuerdo a antecedentes de la historiografía, se trataba de indios fugados, colonos pobres y mestizos discriminados, identificados como "vagabundos", "chusmas" y "gentes mal entretenidas" (Mellafe, 1959: 111; Salazar, 2000: 26), cuya existencia contribuirá a alimentar la representación de La Chimba como las tierras del desorden y la barbarie.

En el año 1598, La Chimba acogerá gran cantidad de migrantes que escapan de las ciudades del sur destrozadas por las guerras entre españoles y mapuches. De allí nacen las primeras formas de urbanización de este lado de la ciudad. La población aumentará

\footnotetext{
6 René León Echaiz (1975) consigna que, después del primer parlamento de Pedro de Valdivia con los caciques de la comarca, el cacique Millacura, del Maipo, le habría aconsejado al español levantar el campamento de La Chimba y pasar a fundar la ciudad a la orilla sur del río, en los terrenos del cacique Huelén Huara. Las razones que habrían movido a uno para dar el consejo y al otro para aceptarlo, contienen muchos de los significados y representaciones ocultas de esta "otra banda del río".
} 

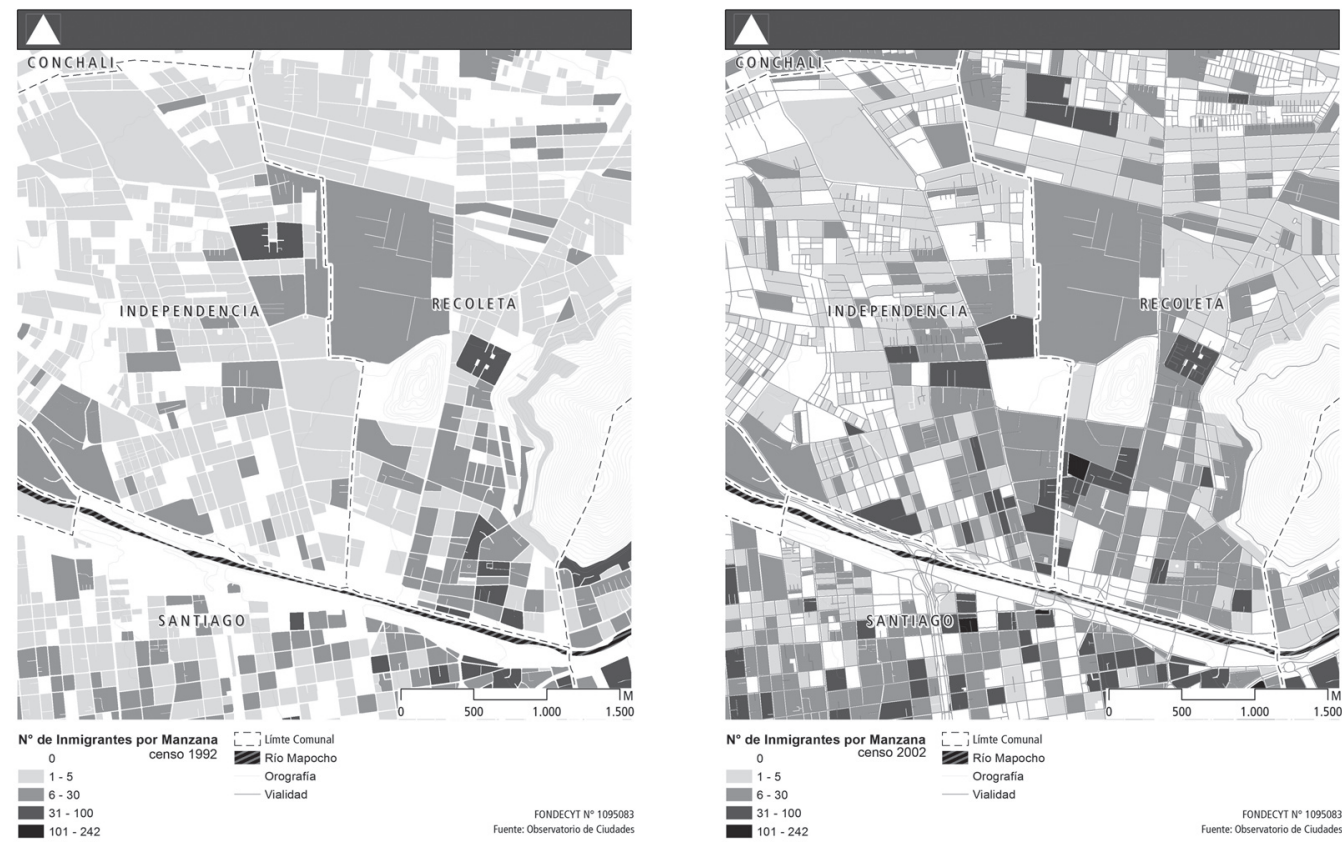

Fuente: Elaboración propia sobre la base de Observatorio de Ciudades UC / INE 1992 - 2002.

progresivamente, cobijando a indios, mestizos y españoles empobrecidos, dedicados principalmente a las labores de agricultura y manufactura artesanal a menudo apostada a las orillas del río Mapocho que limpiaba los residuos tóxicos que de allí emanaban.

Hasta el siglo XIX, el crecimiento poblacional de La Chimba fue más bien lento y de carácter gradual, las grandes extensiones de tierra y chacras cultivadas junto a la población que no terminaba de asentarse completamente en estas tierras, hacía difícil una urbanización y control sobre el territorio. Puerta de entrada y salida hacia el norte, La Chimba, se configura desde sus inicios como un lugar de tránsito tanto para el ejército como la población errante en busca de mejor destino. La construcción del puente Cal y Canto (1765-1782) más que asegurar el tránsito y comunicación entre ambos lados del río, se construye justamente de la necesidad de Santiago de salir hacia Lima, atravesando La Chimba.
Desde la segunda mitad del siglo $X X$, el territorio correspondiente a La Chimba sufre un proceso significativo de pérdida de población, situación común en la mayor parte de las comunas pericentrales del Gran Santiago (Borsdorf \& Hidalgo, 2005). De acuerdo a los datos del Censo de 1982, La Chimba poseía un poco más de 41.000 habitantes, los que para 1992 descienden a 34.002 y 29.344 en 2002. Sin embargo, dicho proceso no se corresponde con la evolución demográfica de los inmigrantes en este mismo territorio. Por el contrario, se puede constatar un explosivo crecimiento entre el período 1992-2002 (1982: 715 inmigrantes; 1992: 736 inmigrantes; 2002: 2.383 inmigrantes). Esta situación coincide con los procesos de inmigración andina a partir de 1996, responsables de más del $50 \%$ de la inmigración de población peruana (ver figura 3), colombiana y ecuatoriana (Germaná, 2005). En efecto, el análisis demográfico permite constatar, a través de los datos territorializados a nivel de manzanas (ver Figura $\mathrm{N}^{\circ} 1$ ), una elevación de la pobla- 
Figura $\mathrm{N}^{\circ} 2$

Precio del suelo y servicios por manzana
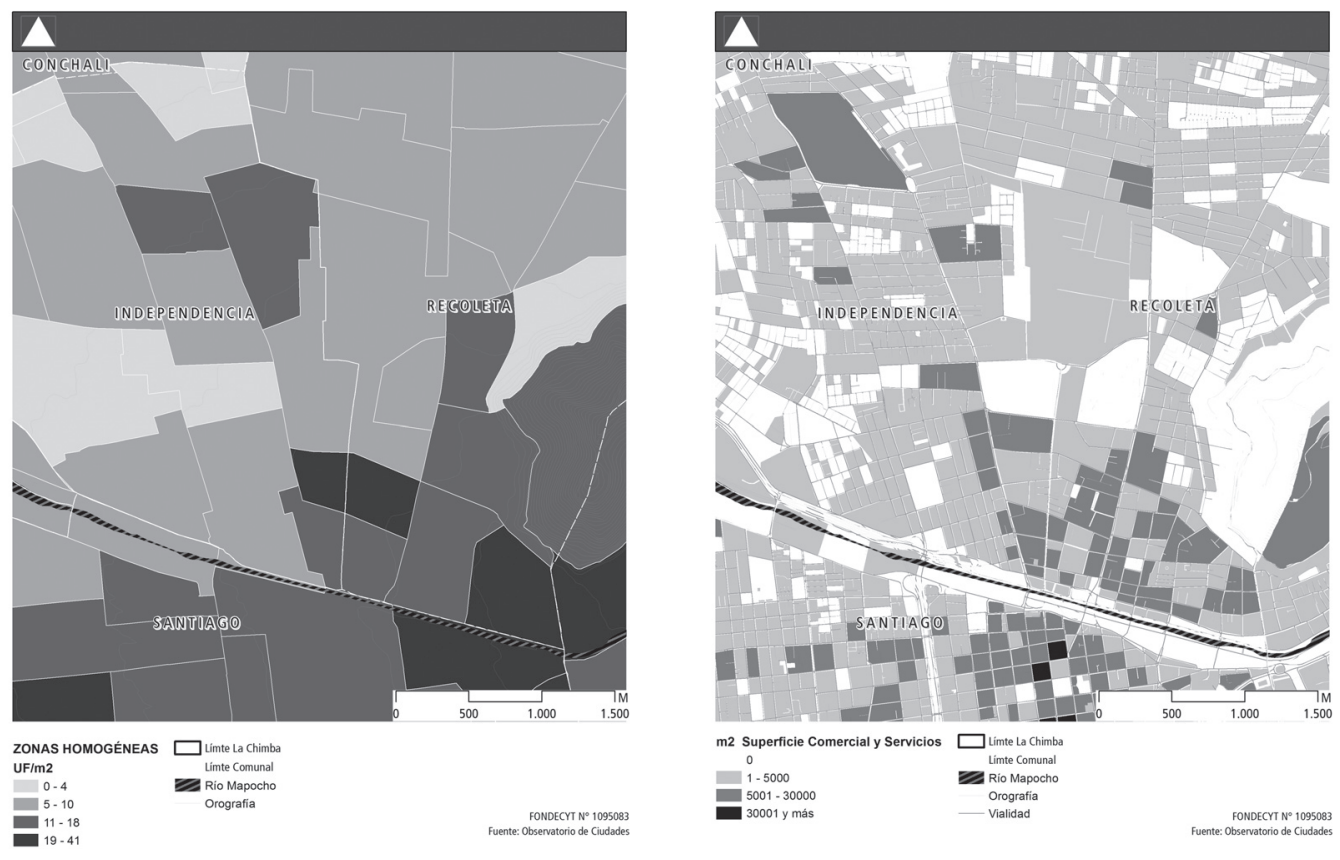

Fuente: Elaboración propia sobre la base de Observatorio de Ciudades UC 2009 / Centro de Inteligencia Territorial UAI, 2011/ SII, 2004.

ción inmigrante para el periodo señalado 7 , con una clara concentración en torno a los ejes de avenida La Paz e Independencia. Este hecho se suma a las concentraciones precedentes en avenida Recoleta (árabes, españoles, palestinos, coreanos, entre otros).

Si bien el crecimiento de inmigrantes ha sido considerable durante el último período intercensal ${ }^{8}$, la localización de los mismos no es aleatoria en el Gran Santiago. Responde a diferentes factores, dentro de los que destacan la cercanía al trabajo, las redes familiares y sociales y la posibilidad de acceder a bienes y servicios materiales -tales como la vivienda- (Huete y Muñoz, 2011). La Chimba no es la excepción. En la decisión de loca-

7 Un incremento para la zona representada en el plano de 5.390 (1992) a $11.113(2002)-51 \%$. INE 1992- 2002.

8 Los inmigrantes han aumentado de 63.690 en 1992 a 113.227 en 2002-43\% - (Santiago Metropolitano). Datos INE 1992-2002. lización destaca la cercanía a importantes centros de trabajo en el entorno inmediato, tales como Patronato, La Vega; y al sur del río Mapocho, Santiago Centro. Esta última comuna concentra la mayor cantidad de metros cuadrados de servicios y comercio del Gran Santiago, convirtiéndose en uno de los mayores atractores de población flotante por motivos de trabajo de Santiago ${ }^{9}$ (SECTRA, 2006).

Otro punto a favor para el emplazamiento de inmigrantes en La Chimba es el bajo precio de suelo del sector, situación anómala tomando en consideración que la comuna de Santiago se encuentra colindante al sur del área referida de estudio. Esta zona, específicamente el centro histórico, es considerada

\footnotetext{
9 La comuna de Santiago, de acuerdo a la Encuesta Origen Destino de Sectra 2006, es la que atrae más viajes del Gran Santiago con un 12,21\% de todos los realizados por motivos de trabajo, le sigue la comuna de Las Condes con un 7,43\% .
} 
por diversos estudios como el Central Business District (CBD) del Gran Santiago (Ortiz y Escolano, 2005), lo que presupone los precios más altos de la ciudad $\left(16 \mathrm{UF} / \mathrm{m}^{2}\right.$ en promedio con peaks que varían entre 40 a 120 $\left.\mathrm{UF} / \mathrm{m}^{2}\right)^{10}$. En La Chimba sin embargo, se produce una brusca baja de precios, a modo de hipótesis esta situación que se podría explicar por su característica de territorio de frontera, traducido en este caso por el río Mapocho y su consiguiente impacto en la accesibilidad del sector. La excepción corresponde a la zona sur oriente de La Chimba. Esta destaca por sus precios de suelo más altos, lo que coincide con la localización de las residencias de inmigrantes palestinos y coreanos, y por ser un área que progresivamente ha sido permeada por el desarrollo inmobiliario (en torno a avenida Recoleta y avenida Perú). Por otra parte, la localización de la nueva oleada de inmigrantes se concentra en los lugares de precios de suelo más bajo (ver Figuras $\mathrm{N}^{\circ} 1$, $\mathrm{N}^{\circ} 2$ y $\mathrm{N}^{\circ} 3$ ).

La revisión de los datos censales a nivel de manzana correspondiente a los inmigrantes confirma su procedencia andina. Ello se evidencia en los sectores con mayor concentración de población foránea en La Chimba. Destaca especialmente la presencia de inmigrantes peruanos. La migración de este país para los censos de 1982 y 1992 se mantenía apenas por sobre el 5\% del total de inmigrantes de La Chimba, muy por debajo de otras nacionales destacadas, como los coreanos. No obstante, para el año 2002 los peruanos pasan a ser el $68 \%$ de los inmigrantes totales de La Chimba. Este hecho se traduce en el tercer factor de localización, la creación de redes familiares, o bien, de conocidos y compatriotas, lo que sirve como un atractor más, sumado al tema de precios de suelo y a la cercanía a fuentes laborales.

Como se pudo observar con los precios de suelo, los procesos de difusión urbana

\footnotetext{
10 La teoría indica que las zonas del entorno inmediato al Central Business District deben tener valores similares a este último, aunque levemente más bajos. De esta forma a medida que la distancia aumenta, la influencia ejercida por el CBD, en cuanto a la difusión de precios de suelo, disminuye progresivamente (Muñiz et al., 2005).
}

Figura $\mathrm{N}^{\circ} 3$

Procedencia de inmigrantes por manzana y nacionalidad.

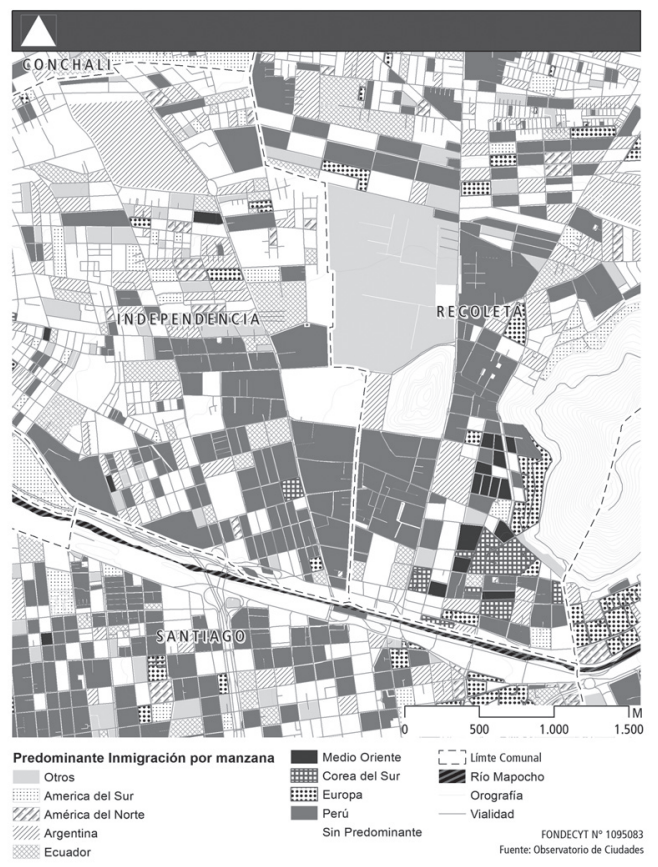

Fuente: Elaboración propia sobre la base de Observatorio de Ciudades UC / INE 1992 - 2002.

normal tienen una penetración mucho menor en La Chimba, situación que podría verificarse a la par del análisis de la información sociodemográfica territorializada a nivel de manzana. Ejemplo de esto es el análisis de Grupos Socioeconómicos (GSE) predominante a nivel de manzana.

En la Figura $\mathrm{N}^{\circ} 4$, se muestra el cambio en la composición del GSE, aumentando la predominancia de grupos C2 (clase media - alta) por sobre grupos C3 y D (clase media baja y clase baja) ${ }^{11}$. Al analizar el territorio con detención se verifica que esta situación se da

\footnotetext{
11 De acuerdo a la variación intercensal 1992-2002 para La Chimba, la población D disminuyó de 4.916 hogares a 3.864 hogares; la población C3 también disminuyó de 3.980 hogares a 3.144 hogares; en contraposición la C2 aumentó de 2.210 a 2.828 hogares. Todo esto debe ser analizado además en el contexto de la pérdida de población en el periodo intercensal $-14 \%$ de disminución- (INE 19922002).
} 
Figura $\mathrm{N}^{\circ} 4$

Grupos socioeconómicos predominantes por manzana
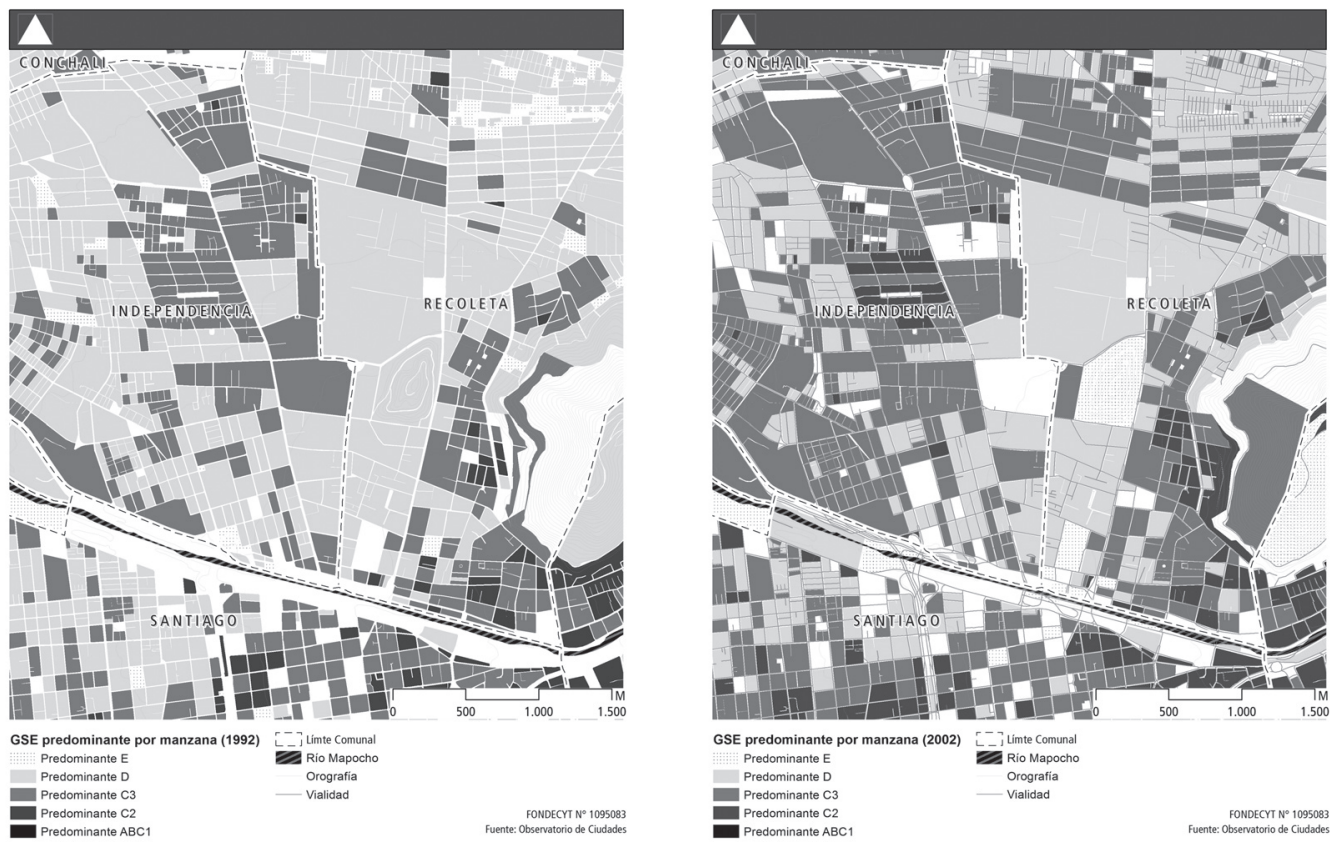

Fuente: Elaboración propia sobre la base de Observatorio de Ciudades UC / INE 1992-2002.

de forma focalizada en torno a los llamados "corredores de desarrollo" como son avenida Independencia y Recoleta, dejando a un amplio territorio sin una evolución clara, lo que muestra nuevamente la baja permeabilidad urbana de La Chimba ${ }^{12}$. No es coincidencia entonces la correspondencia espacial entre las manzanas de más bajo GSE, menores precios de suelo y mayor crecimiento de inmigrantes. Tampoco la diferenciación entre los primeros inmigrantes, que consiguen una holgura económica, y los nuevos, que arriendan y subarriendan a sus predecesores en condiciones de habitabilidad más precarias. Un índice que ayuda a verificar esta realidad

\footnotetext{
12 Este proceso de evolución del período intercensal 1992-2002, no es excluyente de este territorio. En el caso de la zona sur de Santiago se puede verificar una evolución similar en torno a los llamados "corredores de desarrollo" (Gran Avenida, Vicuña Mackenna, avenida La Florida y en el poniente, avenida Pajaritos). En todos ellos se ha producido un aumento de los ingresos, lo que ha permeado a su entorno inmediato.
}

es el hacinamiento, que para el caso de esta investigación se considera por sobre las 2,5 personas por recinto habitable.

En el caso del hacinamiento nacional se observa una cierta homogeneidad territorial con correspondencia a disminuir del $25 \%$, a medida que el grupo socioeconómico predominante es C3 y C2. Al revisar los datos de vivienda y hogares de los extranjeros, quedan patentes las condiciones de hacinamiento derivadas del subarriendo a inmigrantes latinoamericanos, situación que se concentra fuertemente en el sector de La Chimba de menor ingreso (ver Figura $\mathrm{N}^{\circ} 5$ ).

Por su parte, los datos de ocupación no muestran un cambio significativo entre la mano de obra nacional e inmigrante (con excepción en el tramo de profesionales y técnicos $\left.{ }^{13}\right)$. En general, esta última tiene predo-

\footnotetext{
13 Filtrando solo los inmigrantes la proporción de profesionales y técnicos bajan el 1\%; en el caso nacional corresponden al 13 y $18 \%$ respectivamente.
} 
Figura $N^{\circ} 5$

Hacinamiento inmigrantes y nacional - 2002
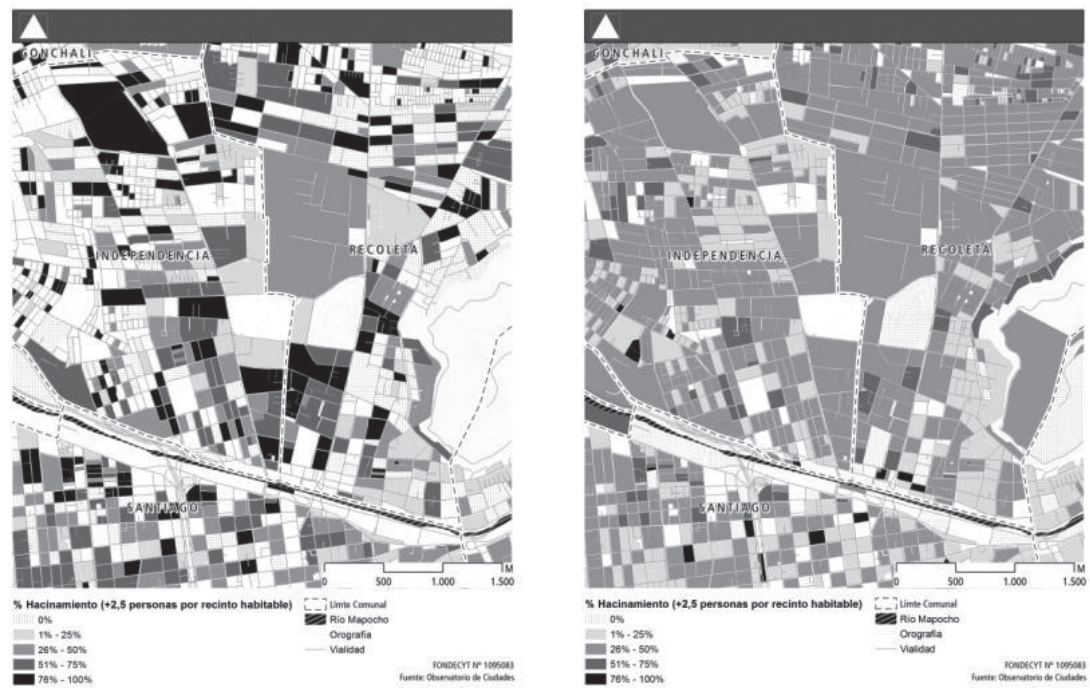

Fuente: Elaboración propia sobre la base de Observatorio de Ciudades UC / INE 1992-2002.

Figura $\mathrm{N}^{\circ} 6$

Ocupación laboral predominante - 2002
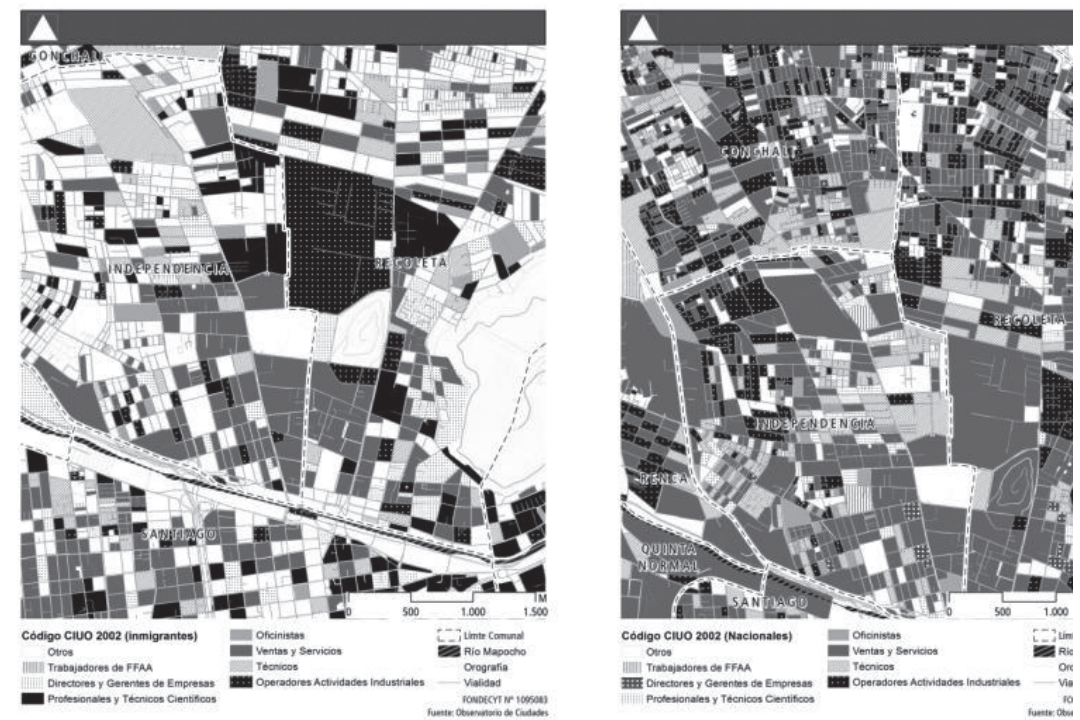

Fuente: Elaboración propia sobre la base de Observatorio de Ciudades UC / INE 1992-2002.

minancia en el sector terciario $(49,5 \%)$, dedicado a ventas y servicios, lo que corresponde a las fuentes laborales más cercanas (La Vega, Patronato, Santiago Centro). En segundo lugar destacan las actividades secundarias (industriales $-17,6 \%-$ ), también relacionadas con el sector, aunque vale la pena establecer una diferencia cuando se analiza La Chimba 
y su entorno comunal. En la Figura $\mathrm{N}^{\circ} 6$ se observa una gran proliferación de la actividad secundaria para la mano de obra nacional al norte, poniente y nororiente de La Chimba, sin embargo tal situación no se observa para el territorio analizado.

Esto en parte podría explicarse por la predominancia de la ocupación de ventas y servicios, pero también por las características de los usos de suelo en La Chimba. La estructura de usos en su territorio no es homogénea, sino que corresponde a un mix de usos de suelo, entre residenciales, comerciales, de servicio e incluso industriales y de bodegaje. Esta mezcla se evidencia a distintas escalas, desde la manzana, e incluso en muchos casos, dentro de una misma vivienda como lo ha demostrado la investigación etnográfica.

\section{La Chimba en la cartografía histórica del siglo XVII-XIX}

En la fundación de las ciudades del Nuevo Mundo, las Leyes de Indias establecieron normas urbanísticas basadas en los preceptos de Hipódamo de Mileto, inventor de la cuadrícula. Los anchos de las calles estaban definidos en base a la latitud, buscando ventilaciones, pero también que los bajos edificios proyectaran su sombra sobre ese espacio. Dicha geometría operaba a su vez como ideario para la ciudad en su conjunto; en el caso de Santiago de Chile, incluso más allá del valle formado entre el río Mapocho y la Cañadilla. Sin embargo, la cartografía nos muestra que -a pesar del ideario- ello no siempre logró plasmarse hacia el borde norte del río Mapocho. En términos de la "Imagen urbana", la presencia del río en las representaciones cartográficas de Santiago, permite comprender la centralidad que este pasará a adquirir en el tiempo, no solo como interface (columna o fisura) de este territorio urbano, sino también como significante que orienta las lecturas posibles de esta ciudad tempranamente dividida en dos: la ciudad "propia" que sería la fundada, al sur del río, rigurosamente obediente a la cuadrícula; y la ciudad "bárbara", La Chimba, al norte del río, desordenada y ajena a la imposición de dicho ideario urbanístico.
En términos de "los lugares significados", desde el siglo XVII hasta el siglo XIX, el paisaje de La Chimba era representado de manera discontinua y agreste. Grandes chacras y solares, se entremezclaban con pequeñas formaciones de carácter semiurbano como rancheríos y poblaciones espontáneas. En las representaciones cartográficas del siglo XVII, La Chimba apenas se insinúa en los planos del trazado urbano de Santiago. La Chimba y sus sectores aledaños eran terrenos agrícolas, con pequeñas quintas, chacras de cultivos y molinos que alimentaban a la ciudad en formación (Latcham, 1941; Jocelyn Holt, 2000). A pesar de la importancia que esta zona poseía en la vida social y económica de la naciente ciudad de Santiago (De Ramón y Gross, 1985; De Ramón, 2000), ella será representada como un lugar marginal, difuso y de los "extramuros" de la ciudad.

\section{La Chimba a semejanza de la ciudad europea}

El plano del padre jesuita Alonso de Ovalle, constituye uno de las primeras representaciones cartográficas donde La Chimba adquiere un lugar explícito en el plano de la ciudad. Hijo de encomenderos, y nacido en Chile, publica su libro "Histórica relación del Reyno de Chile y de las misiones y ministerios que en él ejercita la Compañía de Jesús" en 1646, en la ciudad de Roma. No es difícil comprender que su representación cartográfica de Santiago, esté signada por la impronta y forma de la ciudad europea y la presencia eclesial de sus instituciones religiosas.

A diferencia de lo que ocurre en la cartografía posterior, en este plano de comienzos del siglo XVII, el damero de la ciudad del centro o fundacional, cruza hacia el sur de la Cañada y hacia el norte del río Mapocho hasta cubrir La Chimba en su totalidad. El plano fija y refuerza ciertas utopías e idearios sobre la forma y el orden de la ciudad de Santiago. El río, no es quiebre sino simplemente una delgada línea que los principios de la urbanización europea, a través del damero, podrán dominar.

En este plano titulado "Prospectiva y planta de la ciudad de Santiago de Chile" (Figura $N^{\circ} 7$ ), la ciudad aparece perfectamente cua- 
driculada y las manzanas divididas a su vez en doce pequeñas cuadrículas. Idealización de "una ciudad hecha a compás y cordel", y que de acuerdo al dictamen del rey Carlos $\checkmark$ de España, se asemejará a todas las demás ciudades americanas. La representación cuidadosa de iglesias, conventos, monasterios y órdenes religiosas en todos los puntos de Santiago, celebran a su vez una ciudad de la cristiandad. El cerro Santa Lucía (patrona de la buena vista) y su cruz, situado en el "arriba" o norte del plano, dominan y velan por la ciudad toda (Martínez, 2007: 5).

La ribera norte del río Mapocho, La Chimba se la representa en la misma perspectiva ideal. A pesar de no estar urbanizada, se le impondrá el damero uniformándola, ordenándola e integrándola al conjunto de la ciudad. Visión idealizada con la que, en tiempos de guerra, se celebra la ciudad como "el arquetipo o paradigma de la tranquilidad y paz, el lugar más seguro del Reino" (De Ramón. 2000: 42). En este sentido, la ciudad ideal del padre De Ovalle, más que pretender una representación planimétrica y topográfica, constituye la utopía de la ciudad europea en el nuevo mundo. Nace así la ciudad "de la nueva utopía civilizadora" no solo en Chile sino para todo el nuevo continente (Martínez, 2007: 5).

\section{La Chimba, puerta de entrada de la ciudad militar}

A comienzos del siglo XVII, Amadeo Frezier, ingeniero militar francés, contratado por el rey Luis XIV, Ilegó a Chile para realizar estudios astronómicos con objeto de perfeccionar la cartografía americana. En el plano de Frezier de 1712, que representa la ciudad castrum militar de la conquista, se muestra un Santiago "desde" el Perú (norte abajo) y que mira "hacia" el territorio de la Araucanía a conquistar (sur arriba). Allí La Chimba -casi un siglo después de Ovalle- aparece solo insinuada en su traza básica, contrastando con el damero regularmente construido en el centro de la ciudad; el río marca la frontera de quiebre entre ambos trazados. En el plano se puede apreciar el pequeño cerro Santa Lucía en su parte superior. Las manzanas perfectamente cuadriculadas nos hacen recordar el plano de Alonso de Ovalle, pero en este de Frezier, se destacan y dibuja acequias que se
Figura $\mathrm{N}^{\circ} 7$

Prospectiva y planta de Santiago de Chile, Alonso de Ovalle, 1646

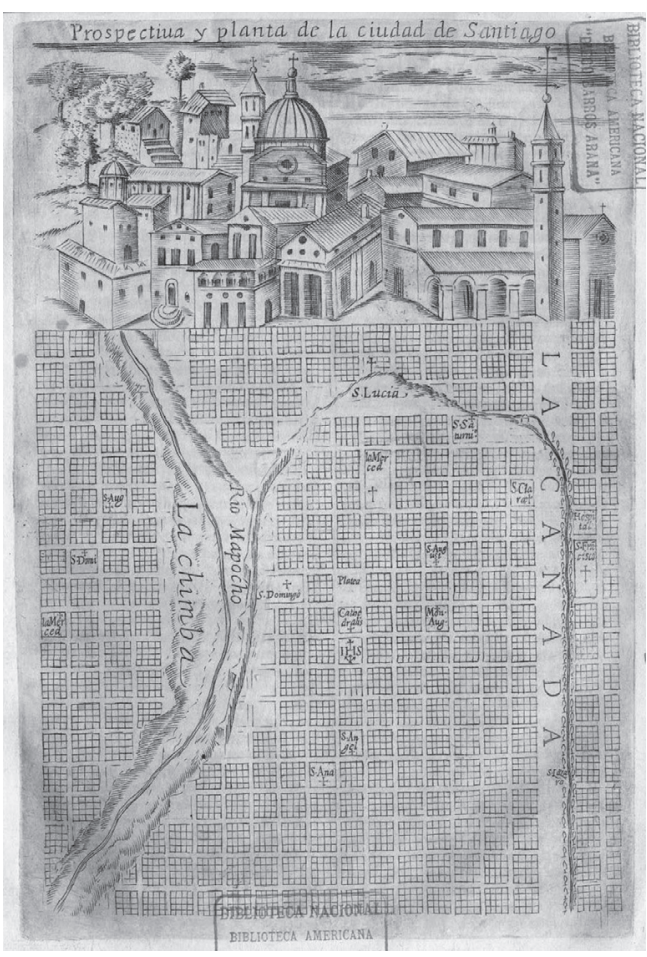

Fuente: Martínez, 2007.

desprenden del río Mapocho y alimentan la ciudad, formando un gran huerto. La ciudad aparece más pequeña, con 23 plazas, instituciones y puentes que conectan ambas orillas del río. Destaca el "Pont Ruine" o el puente de palo, ubicado frente a la actual Avenida Recoleta. La Chimba aparece como una prolongación de la ciudad de Santiago, pero esta vez el damero apenas atraviesa el río Mapocho, quedando solo insinuado e incompleto. La Chimba es representada como tierra desconocida y puerta de penetración hacia el sur (Figura $\mathrm{N}^{\circ} 8$ ).

\section{La Chimba del naturalismo}

De nacionalidad francesa y profesión botánico, Claudio Gay fue contratado por el gobierno de Chile en 1830, y como empleado gubernamental, realizó en 1834 uno de los planos más significativo de la cartografía de Santiago (Figura № 9). En este, la ciudad aparece colorida y destacan los detalles en la 
Figura $\mathrm{N}^{\circ} 8$

Plano de Amadeo Frezier, 1712.
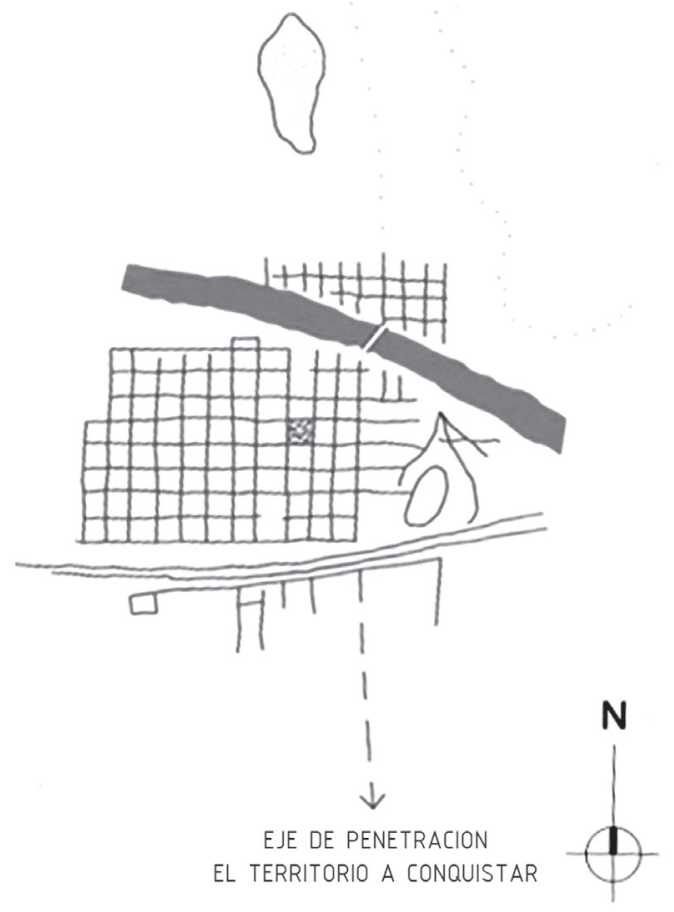

Fuente: Croquis interpretativo del plano de Frezier, Márquez (2005).

geografía, sobre todo la gran hoya hidrográfica del río Mapocho, y sus múltiples brazos. El plano cambia de dirección (el norte está en la cabecera del plano), y la realidad planimétrica es representada fielmente junto a una gran cantidad de instituciones no solo religiosas, sino también edificios públicos, plazas, entre otros.

La Chimba ya no es representada como una extensión de la ciudad, sino más bien como un espacio distinto, escasamente urbanizado, de chacras y grandes extensiones de tierras agrícolas. Como buen naturalista, representa el cerro Blanco, el cerro San Cristóbal e instituciones religiosas (Iglesia de la Estampa, Recoleta Dominica, Recoleta Franciscana y el Carmen Bajo). Las principales vías de La Chimba aparecen con cierto grado de consolidación. La Cañadilla denota su carácter de principal vía de acceso a la ciudad desde el norte, siendo representada con mayor amplitud que la mayoría de las calles de la ciudad urbanizada. Asimismo la calle de la Recoleta, comienza a consolidarse como una vía alternativa en este sector; y aparecen nuevos callejones que unen La Chimba de lado a lado. La Chimba, pierde así su condición de tierra incógnita y adquiere su propia impronta.

\section{La Chimba de la ciudad regulada}

Ernesto Ansart, ingeniero, es el primero en realizar un plano estrictamente administrativo y con proyecciones urbanas. El plano de 1875 muestra Santiago nuevamente (el norte abajo) vuelto hacia la Araucanía (sur hacia arriba) que debe ser pacificada. Ansart incorpora al trazado urbano algunas proyecciones como el camino de cintura, la canalización del río Mapocho, las actuales comunas de Recoleta e Independencia en un momento en que el intendente Benjamín Vicuña Mackenna se propone realizar modificaciones en la estructura urbana, a través de su Plan de Transformación de la ciudad el año 1872. En el ordenamiento territorial del plano se observa un crecimiento en la ciudad, particularmente orientado hacia el sur (Figura $N^{0} 10$ ).

En relación a La Chimba, se conserva la toponimia de las calles principales, pero el territorio es incluido en el trazado urbano y en las categorías de orden administrativo. Así, por ejemplo, las comunas de Recoleta e Independencia son ahora subdelegaciones (14 y 15 respectivamente). Este ordenamiento termina con el carácter rural de La Chimba y se lo incluye en la traza urbana y administrativa de la ciudad. El plano a su vez, destaca desde Independencia al poniente, la Población Ovalle intentada en términos de su urbanización y vialidad. Junto a las políticas de higiene y de urbanización que se aplican también en La Chimba, el sector norte de la ciudad, queda al menos en términos administrativos integrado a las normativas $y$ regulaciones urbanas de la ciudad de Santiago. Aun así, La Chimba preservará en su traza irregular y densa, dando cuenta de un ordenamiento territorial propio que se hace a la medida de sus ocupantes, más que de las políticas de regulación y ordenamiento territorial.

En síntesis, el siglo XIX, considerado como el siglo de oro de la cartografía chilena, es el período en que cartógrafos, naturalistas, ingenieros y científicos, retratan y representan 
Figura $\mathrm{N}^{\circ} 9$

Plano de la ciudad de Santiago, Claudio Gay, 1834

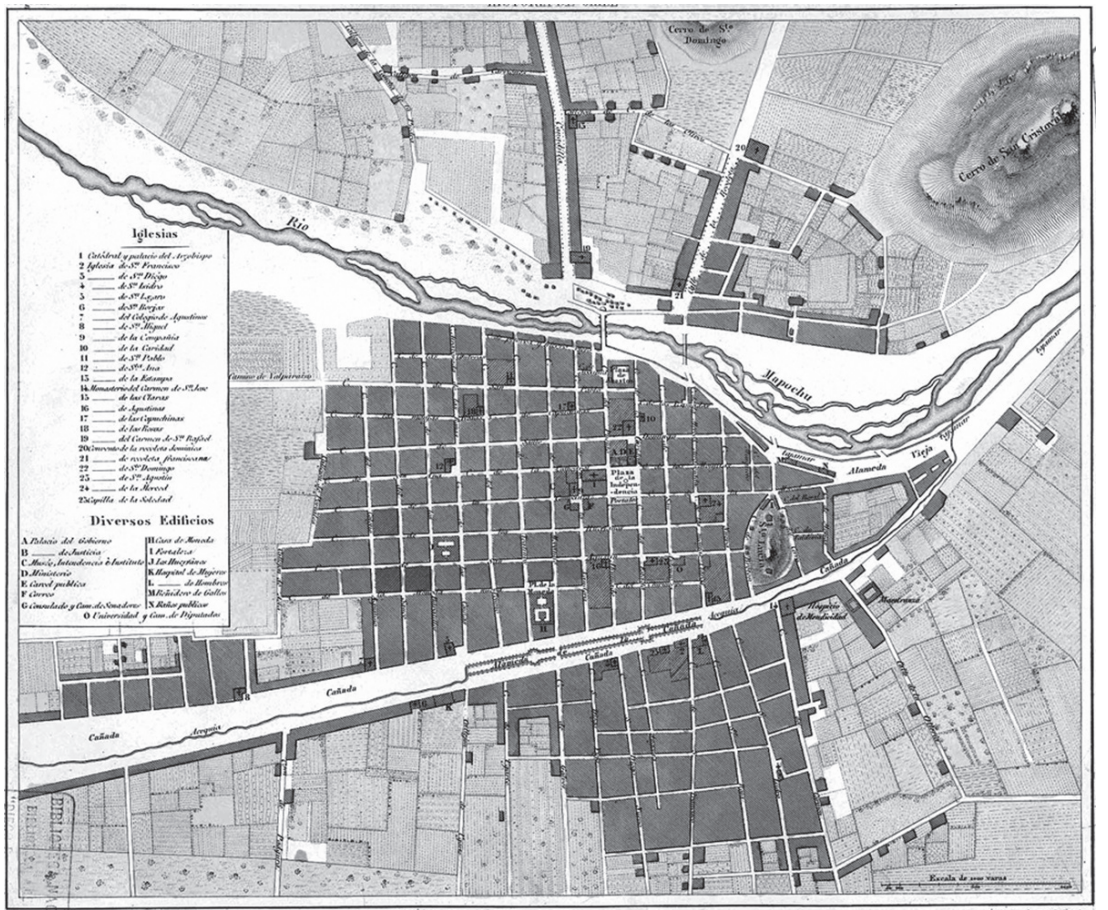

Fuente: Martínez, 2007.

Figura $\mathrm{N}^{\circ} 10$

Plano de Ernesto Ansart, 1872

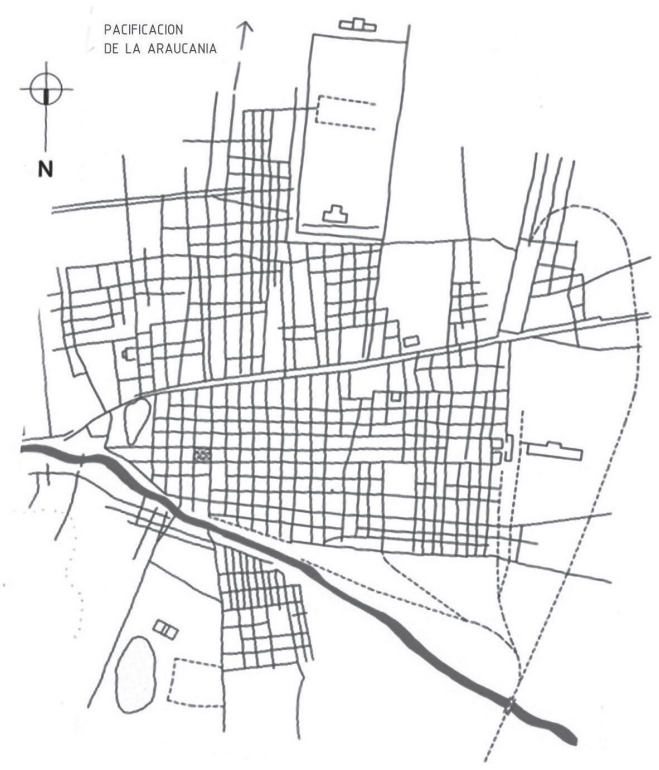

Fuente: Croquis interpretativo, Márquez, 2005. 
la ciudad con el propósito de asentar el ideario de un Estado Nación en germen. Llegará el siglo XX y con ello se comenzará a perder la semantización de la iconografía cartográfica, momento que se inicia con los planos de las instituciones republicanas que adscriben las convenciones internacionales, colocando siempre el norte hacia arriba. Es en este momento de racionalización que no solo se pierde la maleabilidad de significados que contienen los puntos cardinales de la geografía (Márquez, 2005), sino también, los planos pierden la autoría individual, para transformarse en instrumento de planificación pública. Con ello los planos tienden a homogeneizarse y a obviar los rasgos identitarios de los territorios, destacándose aspectos comunes tales como las vías, comercio e instituciones.

La Chimba, aunque participa y se mimetiza en esta representación cartográfica, en términos de su ocupación y forma, ella seguirá resistiendo al control y ordenamiento central. $\mathrm{Si}$ el ideario fundacional era representarla como un territorio que participaba del ideario del damero y la cuadrícula de la ciudad oficial; con el tiempo las representaciones cartográficas hablan de un terreno más bien desordenado, rural y/o escasamente urbanizado. Esto es, un territorio, que a pesar de los idearios y utopías de los representantes de la corona o los propósitos ordenadores de la planificación urbana, conserva una traza y un ordenamiento distintivo al resto de la ciudad del centro cívico.

\section{La Chimba en los mapas cognitivos del siglo XXI}

Si los planos históricos representan una "imagen urbana" de La Chimba desde el centro de la ciudad, es decir, desde el lado sur del río Mapocho, los mapas cognitivos de sus actuales habitantes tenderán a representarla desde el lado opuesto. Es decir, La Chimba aparece representada y observada desde el lado norte del río, y es desde allí que la ciudad del casco histórico se observa. En términos de esta "imagen urbana", La Chimba representa para sus habitantes la posibilidad de integración a la vida de la ciudad, de allí los puentes, las rutas que conectan a los servicios y al comercio de la ciudad. Pero La Chimba, también es cobijo, resguardo que da la forma cerrada y precisa del trazo con que se la representa. Cobijo que se representa por la delgada franja -frontera e intersticiodel río Mapocho. Franja que protege, pero también conecta y abre hacia el centro de la ciudad de la cuadrícula y el centro histórico.

En este ejercicio de representación de La Chimba, se observa que tanto para los habitantes chilenos como para los inmigrantes, los "lugares significados" son siempre aquellos que acogen los afanes y trayectos cotidianos y laborales. Prácticas, usos y ocupaciones, que en su mayoría se realizan desde La Chimba hacia el centro de la ciudad. La materialidad que acompaña dichos lugares -carros, utensilios, camiones, etc.- refuerzan el significado de los lugares como espacios propios. En ellos están también los iguales -otros migrantes, otros trabajadores-, pero por sobre todos las oportunidades de trabajo e integración a la ciudad mayor.

Las representaciones de la "imagen urbana" y los "lugares significados" de los habitantes de La Chimba, son coherentes y dan continuidad en gran parte a las representaciones que se instalaran desde la cartografía histórica de los siglos XVII al XIX.

\section{Integración a la ciudad ideal}

En el siguiente croquis (Figura $N^{\circ} 11$ ), una vecina chilena representa la ciudad de Santiago destacando el Palacio de La Moneda, el río Mapocho y sus muros de contención, el transporte, la bandera chilena y un par de árboles. Al solicitársele que dibuje La Chimba (Figura $\mathrm{N}^{\circ} 12$ ), su barrio, ella expresa que "es lo mismo", Santiago es La Chimba y La Chimba es Santiago, lugar de conectividad y acceso a todo. Entre los croquis las semejanzas son evidentes: donde estaba La Moneda, ahora está el cité en el que habita; donde estaba el bus, ahora está el carro que transporta alimentos del mercado de La Vega; los árboles son los mismos; solo agrega el almacén donde ella compra. La Chimba no es gueto ni población, ella por definición está amarrada a la ciudad en su totalidad; ella es posibilidad de acceso a la ciudad ideal de los signos patrios y modernos, pero a una escala más pequeña y siempre abierta a los afanes de la vida cotidiana y barrial. Un mundo en sí mis- 
Figura $\mathrm{N}^{\circ} 11$

Santiago, 2011

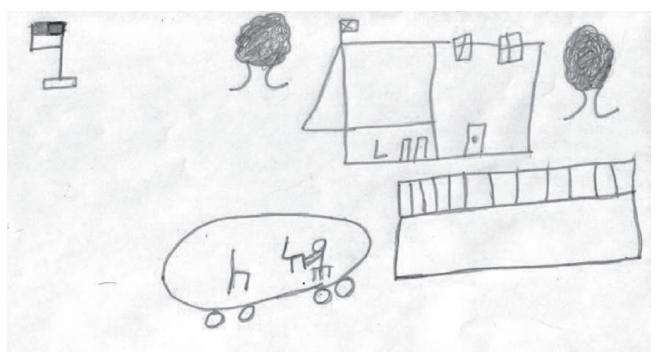

Fuente: Croquis de vecina chilena de La Chimba. Entrevista F. Cottet, FONDECYT N¹095083, 2011.

Figura $\mathrm{N}^{\circ} 12$

La Chimba, 2011

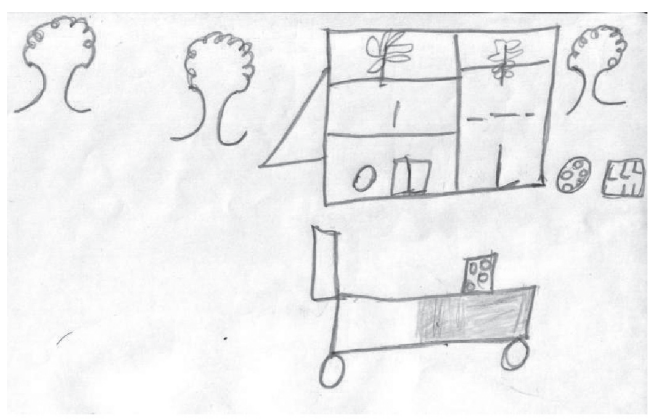

Fuente: Croquis de vecina chilena de La Chimba; entrevista F. Cottet, FONDECYT N¹095083, 2011.

mo, pero cercano y dialogante con Santiago, metrópoli y capital.

\section{Frontera y cobijo}

En el siguiente croquis (Figura $N^{\circ} 13$ ), una mujer chilena dibuja Santiago. El río Mapocho cruza en diagonal toda la ciudad, dividiéndola en dos partes. El río marca la frontera entre La Chimba, su barrio y el centro de la ciudad. Sin embargo, en negro, se destaca el gran puente que conecta ambos lados de la ciudad. En La Chimba se representa avenida Independencia, el mercado de La Vega, sus camiones y sus viviendas pareadas en los pequeños pasajes y cité. En lado opuesto del río, la ciudad del casco histórico, se dibuja la Alameda, La Moneda, Estación Central (trenes) y el transporte. Se observa que desde el centro de la ciudad histórica, una fila de autos y camiones se dirige en dirección a La Chimba.

En el croquis de La Chimba (Figura $N^{\circ}$ 14), la misma mujer representa su barrio rodeado de calles abiertas y conectadas. Al centro de las dos manzanas que perfila, dibuja su cité y el mercado de La Vega como puerta de entrada a su territorio. Lugar estructurante de la vida del barrio, el mercado se representa como un lugar cargado de significado e identidad. La entrevistada relata: "A mí me abandonaron en La Vega, yo crecí ahí, por eso hay gente que me conoce de toda la vida, que me tiene cariño y me cuida igual. Sé que cuento con ellos, porque me conocen de toda la vida. La Vega es mi vida, todo lo que soy es un poco La Vega. La gente ahí es buena, son gente de esfuerzo, saben lo que es vivir en la calle".

Figura $\mathrm{N}^{\circ} 13$

Santiago, 2011

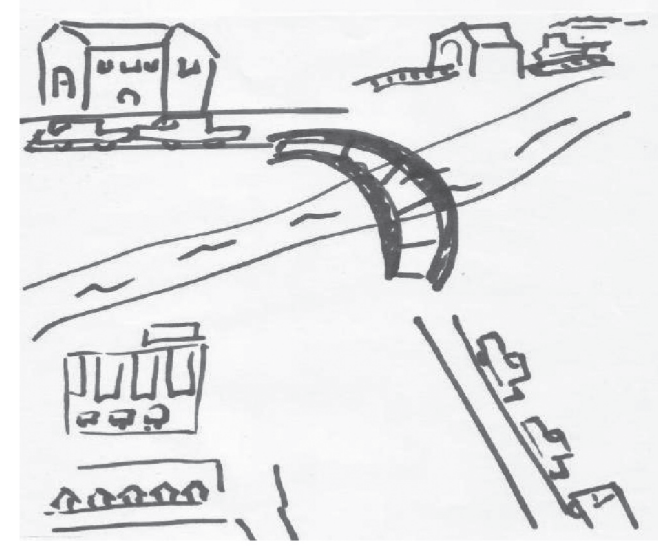

Fuente: Croquis de vecina chilena, entrevista $\mathrm{F}$. Cottet, FONDECYT Nº 1095083, 2011.

\section{La Chimba polifuncional}

Tal como se observa en los croquis siguientes (Figuras $\mathrm{N}^{\circ} 15$ y $\mathrm{N}^{\circ} 16$ ), para los migrantes andinos la representación de Santiago y La Chimba, se centra fundamentalmente en las posibilidades laborales y de integración que este territorio les ofrece. Así lo representan los croquis de un joven hombre peruano. Santiago se reconoce en su cuadrícula, per- 
Figura $N^{\circ} 14$

La Chimba, 2011

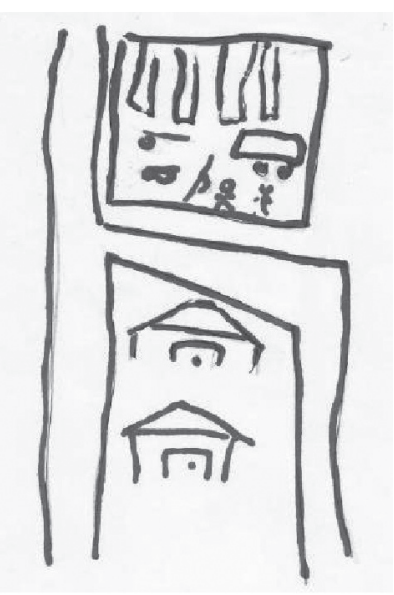

Fuente: Croquis de vecina chilena, entrevista F.Cottet, FONDECYT № 1095083, 2011.

fecta; La Chimba en cambio, en una cuadrícula siempre penetrada y saturada en su orden. Santiago es la promesa del acceso a la modernidad, a los símbolos patrios y eclesiales. Al centro del croquis la Plaza de Armas, la catedral de Santiago, la municipalidad, la casa de correos; y en las calles aledañas, los paseos, pasajes y grandes casas comerciales y bancarias; el metro, las fuentes y monumentos. En el borde inferior del croquis, el damero limita con el río Mapocho; bajo él, solo la Pérgola de las Flores, anunciando que bajo esa línea otra ciudad se ofrece.

El croquis de La Chimba (Figura $N^{\circ} 16$ ), a modo de continuidad con la anterior (Figura $\left.N^{\circ} 15\right)$, representa en su borde superior, la presencia del río Mapocho y sus innumerables puentes. Desde allí se descuelgan las grandes avenidas, calles y pasajes. Espacios saturados por la apretada disposición de viviendas junto a bodegas, espacios de producción, trabajo y estacionamientos de camiones y carros. La representación de La Chimba habla de una ciudadela centrada en la producción, el almacenaje y el comercio. Los lugares se significan y representan en su carácter de distrito comercial y productivo, dejando sumido e irreconocible en ese espacio, el propio lugar de residencia. Hogar que a menudo es también y simultáneamente vivienda - taller - bodega.

En La Chimba, según las representaciones de su habitantes, la condición de umbral -te-

Figura $\mathrm{N}^{\circ} 15$

Santiago, 2011

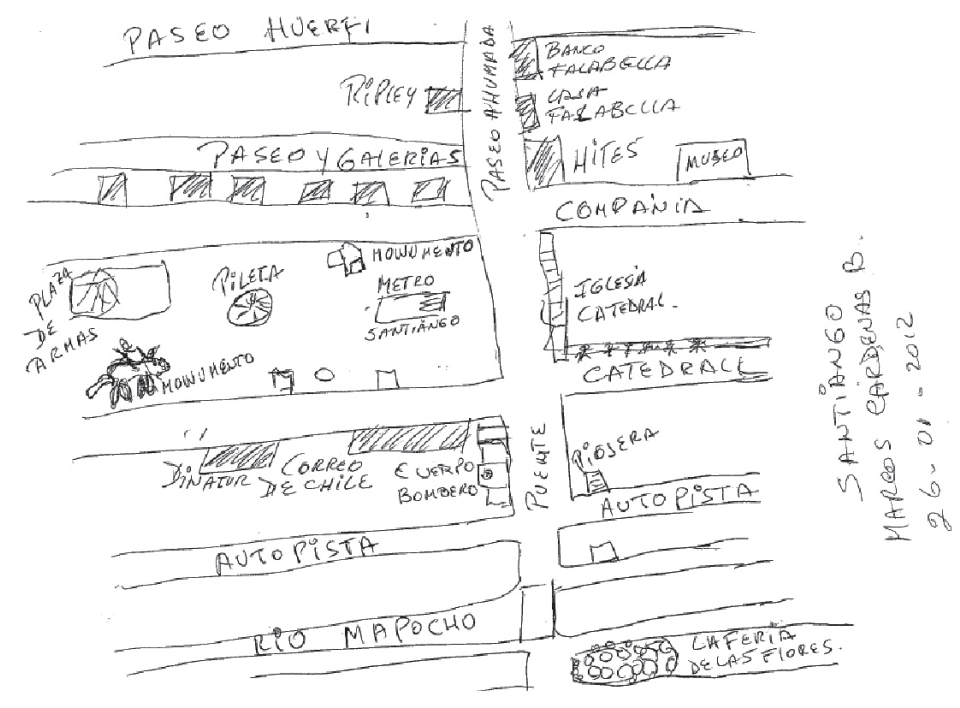

Fuente: Croquis migrante peruano; entrevista Paulo Álvarez, FONDECYT Nº 1095083, 2011. 
Figura $\mathrm{N}^{\circ} 16$

La Chimba, 2011

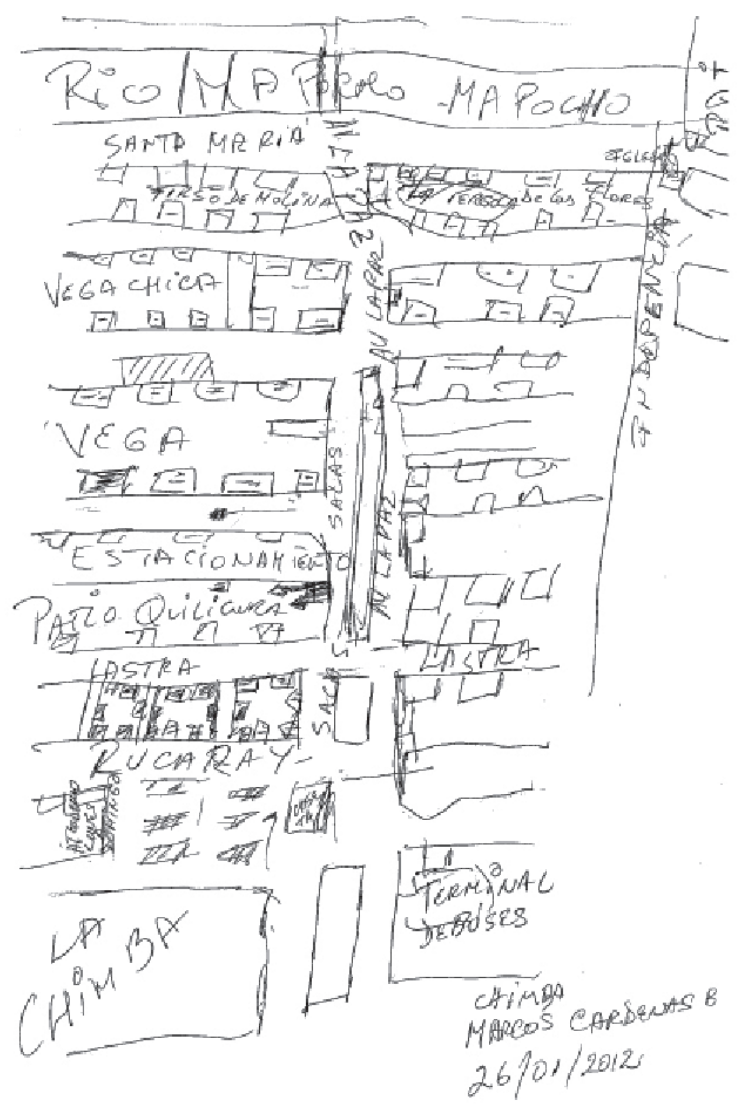

Fuente: Croquis migrante peruano; entrevista Paulo Álvarez, FONDECYT N 1095083, 2011.

rritorio de resguardo y conectividad- ofrece la posibilidad de un habitar flexible a las necesidades y búsquedas de cada uno de sus habitantes. Estos croquis nos advierten que en el habitar de La Chimba, asentamiento siempre precario, nada se amarra definitivamente, ni los cuerpos, ni las formas, ni las arquitecturas, ni los arraigos. Como una ciudadela campamento o asentamiento de frontera, la maleabilidad y capacidad de metamorfosis de los lugares, del cité, de la vivienda, de la caIle, la caracteriza. Esta maleabilidad de los espacios para acoger, esconder o proteger a sus habitantes habla de un habitar donde la zonificación propia a la modernidad y a la planificación urbana, parecieran no tener cabida. Estamos frente a un territorio donde los princi- pios del desorden adquieren fuerza y sentido. Lugar de una plasticidad que poco responde a la lógica estructuradora y segregadora de una ciudad como Santiago. El río como frontera protege, y se encarga de cobijar al inmigrante y trabajador de la "otra banda".

\section{Conclusiones}

El espacio, pensado como territorio o lugar, es siempre una producción social y como tal, está sometido a una constante transformación y polifonía de representaciones. Igualmente ocurre con las identificaciones y significaciones del espacio, no solo porque las relaciones entre los grupos cambian sino porque las posiciones y relaciones de fuerza 
son diversas. Las lecciones que se extraen de este contrapunto entre cartografías oficiales y representaciones subalternas, son muchas. Pero una de las centrales nos advierte que en territorios de frontera, como La Chimba, las representaciones se construyen a múltiples voces y ello tiene consecuencias en la construir del territorio y su habitar.

La revisión de estas cartografías y mapas cognitivos, da cuenta que la territorialidad de La Chimba, comprende espacios físicos discontinuos y ordenados en términos de sistemas de significados diversos y a veces contrapuestos. El análisis de estas representaciones permitió indagar en los imaginarios que se construyen "desde arriba" -viajeros, estudiosos, personeros públicos o eclesiales-, en contraposición a la mirada "desde abajo", habitantes de La Chimba. Desde "arriba" se destacan las representaciones de la ciudad regulada, estratégica y su indomable "trastienda" al otro lado del río Mapocho. Desde "abajo" se caracterizan las representaciones del habitar que hablan de La Chimba, ya no como trastienda sino como ciudadela desde donde se sale y se entra al mundo de la ciudad dominante.

El análisis de la cartografía histórica y de los mapas cognitivos, nos confirma la vigencia y persistencia de La Chimba en su carácter de territorio fronterizo. Si desde la cartografía histórica, La Chimba se nos representa siempre en su condición de "trastienda", resistente y rebelde a la cuadrícula y el orden de la ciudad del centro; a partir de la información que nos arroja el censo y el análisis georreferencial, se nos confirma que La Chimba del siglo $\mathrm{XX}$, perdura en su condición de diferencia con la ciudad central. Condición de enclave que le otorga la barrera natural del río Mapocho, pero sobre todo el carácter de la mixtura sociocultural de sus habitantes.

Desde la perspectiva de los análisis urbanos, la pérdida de población, los bajos precios del suelo y la antigüedad evidente de su arquitectura, permitirían inferir un proceso de abandono y deterioro similar a otras zonas centrales de ciudades latinoamericanas. Sin embargo, tal como nos muestra el análisis censal y también los mapas cognitivos de sus habitantes, La Chimba posee características urbanas de conectividad y de uso del suelo -comercio, industria, servicio y residenciaque refuerzan su carácter de territorio de oportunidades y trabajo a quienes allí residen. Tal como lo señalan las representaciones de sus habitantes, La Chimba, persevera aún en su carácter de enclave que -simultáneamente- cobija y conecta a quienes el centro de la ciudad históricamente no ha querido en su interior. De allí entonces que la figura del río como límite o interface entre La Chimba y el centro de la ciudad, adquieran tanta presencia entre los mapas cognitivos. Si el río protege, el centro recuerda que otros horizontes y otros espacios también son posibles de conquistar. La Chimba es simultáneamente posibilidad de cobijo entre iguales, pero también de integración a la vida urbana, y la posibilidad cierta de hacer de ese espacio un lugar de residencia, de trabajo, integración y prosperidad.

Los mapas cognitivos de sus habitantes dan cuenta, a su vez, de narrativas o relatos culturales del habitar cotidiano, de la riqueza del movimiento, de la posibilidad de un saber hacer, desde donde los habitantes han podido echar raíces, asentarse y hacer de este espacio un lugar simbólico y materialmente propio. Más que trastienda, posibilidad de apertura e integración al universo local y al mundo global. En esta perspectiva, no está de más recordar que la globalización y sus migraciones, han contribuido a cuestionar las categorías socioespaciales y a romper con la idea que las culturas solo se construyen aferradas al terruño. La dinámica socioespacial de la globalización hizo evidente la porosidad de las fronteras de localidades, regiones y naciones; pero también que las identidades pueden ser construidas de manera translocal y desde el movimiento. La espacialidad de La Chimba, históricamente se construyó en estos términos, a menudo en referencia a escalas socioespaciales lejanas y de procedencia diversa; lo local y lo global se reúnen en este espacio. En este sentido, los espacios translocales y fronterizos permiten pensar al citadino, migrante o no, como categoría socioespacial contrahegemónica, simpre vital y cambiante. En los términos de Harley, podríamos concluir que los mapas de La Chimba, aquí analizados, son siempre textos o imágenes retóricas de un mundo social que se piensa a sí mismo. 


\section{Referencias bibliográficas}

ÁLVAREZ, P. De la ocupación al paisaje de frontera. La Chimba de Santiago de Chile. Siglo IV a.C - XIX D.C. Santiago de Chile: Manuscrito, FONDECYT Nº 1095083, 2011.

BAILLY, A. Lo imaginario espacial y la geografía. En defensa de la geografía de las representaciones. Anales de Geografía de la Universidad Complutense, 1989, Vol. 9, p. 36-54.

BORSDORF, A. e HIDALGO, R. Los Mega-Diseños Residenciales Vallados en las periferias de las Metrópolis Latinoamericanas y el Advenimiento de un Nuevo Concepto de Ciudad. Alcances en base al Caso de Santiago de Chile. Scripta Nova: Revista electrónica de Geografía y Ciencias Sociales, 2005, Vol. IX, $N^{\circ}$ 194, Disponible en internet: http://www. ub.es/geocrit/sn/sn-194-03.htm

BOURDIEU, P. La misère du monde. Paris, France: Seuil, 1993.

BURGESS, E. Contribution de Urban Sociology. Chicago: University of Chicago Press, 1963.

BUSTOS, R. Geografía de las Representaciones. Sujeto Acción y Territorio. En: Jornadas de Humanidades. Bahía Blanca, 2005.

DE CASTRO, C. Geografía de la vida cotidiana. Barcelona: Ediciones del Serbal, 1997.

DE CASTRO, C. Mapas Cognitivos. Qué son y cómo explorarlos. Barcelona: Serbal, 2005. Disponible en internet: http://www. ub.es/geocrit/sn-33.htm

DE RAMÓN, A. Santiago de Chile. Santiago de Chile: Sudamericana, 2000.

DE RAMÓN, A. y GROSS, P. (compiladores) Santiago de Chile: características histórico-ambientales, 1891-1924. Londres: s.e. IV, Monografías de Nueva Historia 1, 1985.

DIAZ, R. Imaginario social de la cartografía histórica del barrio de La Chimba. Poder, Significación y simbolismo. Revista Antropología Visual, 2012, N³6, p. 3 - 6.
DI MEO, G. Géographie sociale et territoires. Paris: Nathan Université, 1999.

GERMANÁ, C. La migración internacional: el caso peruano. Lima: Fondo Editorial de la Facultad de Ciencias Sociales, U. Mayor de San Marcos, 2005.

GARCÍA, C.I. y ARAMBURO, C.I. Universos socioespaciales. Procedencias y destinos. Colombia: Siglo del Hombre Editores, 2009.

HARLEY, J.B. La nueva naturaleza de los mapas. Ensayos sobre la historia de la cartografía. México: FCE (Tezontle), 2005.

HUETE H. y MUÑOZ, R. Modelos de Barrios y Lógicas de Localización de la Población Inmigrante. El caso de la ciudad de Sevilla. Scripta Nova: Revista electrónica de Geografía y Ciencias Sociales, 2011, Vol. XV, $N^{\circ}$ 373. Disponible en internet: http://www. ub.es/geocrit/sn/sn-372.htm

JOCELYN HOLT, A. Historia General de Chile I. El retorno de los Dioses. Santiago de Chile: Ed. Planeta, 2000.

LATCHAM, R. Estampas del Nuevo Extremo Antología de Santiago. 1541-1941. Santiago de Chile: Editorial Nascimento, 1941.

LAVÍN, C. La Chimba del viejo Santiago. Santiago de Chile: Zig-Zag, 1947.

LYNCH, K. La imagen de la ciudad. BarceIona: GG Reprints, 1998.

LINDÓN, A. Los imaginarios urbanos y el constructivismo geográfico: los hologramas espaciales. EURE, 2007, Vol. XXXIII, No 99, p. 31-46.

MÁRQUEZ, J. La significación de la orientación en la cartografía de Santiago. En: I.M. PROVIDENCIA. Plan Regulador. Santiago de Chile: Municipalidad de Providencia, 2005.

MARTÍNEZ, R. Santiago de Chile. Los planos de su historia. Siglos XVI a XX. De la aldea a la metrópolis. Santiago de Chile: Municipalidad de Santiago, 2007. 
MELLAFE, R. La introducción de la esclavitud en Chile. Tráfico y rutas. Santiago de Chile: Universidad de Chile, 1959.

MUÑIZ, I.; GALINDO, A. y GARCÍA, M. Descentralización, integración y Policentrismo en Barcelona. Document de Treball, 2005, No5, p. 1-31.

NúÑEZ, F. y SCHOVELIN, R. Modelo de precio de suelo urbano en el Gran Concepción. Revista Ingeniería Industrial, 2002, № 7, p. $47-58$.

ORTIZ, J. y ESCOLANO, S. Crecimiento periférico de Santiago. ¿Hacia la desconcentración funcional de la ciudad? Scripta Nova: Revista electrónica de geografía y ciencias sociales, 2005, No 194 (04), Vol. IX. Disponible en internet: http://www.ub.es/geocrit/sn/ sn-194-04.htm

ROJAS MIX, M. El imaginario: Civilización y cultura del siglo XXI. Buenos Aires: Prometeo Libros, 2006.
ROSALES, J.A. La Chimba Antigua. Historia de la Cañadilla. Santiago de Chile: Editorial Difusión, 1948.

SALAZAR, G. La historia desde abajo y desde dentro. Santiago de Chile: Colección teoría - Universidad de Chile, 2000.

SECTRA. Encuesta Origen y Destino de Viajes del Gran Santiago (EOD). Santiago de Chile: Mideplan, 2006.

SILVA, A. Rito urbano e inscripciones imaginarias en América Latina. Persona y Sociedad, 1996, Vol. X, №1, p.106-115.

TRUFFELLO, R. Detección y medición de la centralidad comercial en el área metropolitana de Santiago. Santiago de Chile: Tesis de magister en Geografía y Geomática-PUC, 2011. 